\title{
The combined use of paclitaxel-loaded nanoparticles with a low-molecular-weight copolymer inhibitor of P-glycoprotein to overcome drug resistance
}

\author{
This article was published in the following Dove Press journal: \\ International Journal of Nanomedicine \\ 21 January 2013 \\ Number of times this article has been viewed
}

\author{
Chung Ping Leon Wan* \\ Kevin Letchford* \\ John K Jackson \\ Helen M Burt \\ Faculty of Pharmaceutical Sciences, \\ University of British Columbia, \\ Vancouver, BC, Canada \\ *These authors contributed equally \\ to this work
}

\begin{abstract}
Two types of nanoparticles were prepared using the diblock copolymer methoxy poly(ethylene glycol)-block-poly(caprolactone) (MePEG-b-PCL), with either a short PCL block length, which forms micelles, or with a longer PCL block length, which forms kinetically "frozen core" structures termed nanospheres. Paclitaxel (PTX)-loaded micelles and nanospheres were evaluated for their cytotoxicity, cellular polymer uptake, and drug accumulation in drug-sensitive (Madin-Darby Canine Kidney [MDCK]II) and multidrug-resistant (MDR) P-glycoprotein (P-gp)-overexpressing (MDCKII-MDR1) cell lines. Both types of PTX-loaded nanoparticles were equally effective at inhibiting proliferation of MDCKII cells, but PTX-loaded micelles were more cytotoxic than nanospheres in MDCKII-MDR1 cells. The intracellular accumulation of both PTX and the diblock copolymers were similar for both nanoparticles, suggesting that the difference in cytotoxicity might be due to the different drug-release profiles. Furthermore, the cytotoxicity of these PTX-loaded nanoparticles was enhanced when these systems were subsequently or concurrently combined with a low-molecular-weight MePEG-b-PCL diblock copolymer, which we have previously demonstrated to be an effective P-gp inhibitor. These results suggest that the dual functionality of MePEG-b-PCL might be useful in delivering drug intracellularly and in modulating P-gp in order to optimize the cytotoxicity of PTX in multidrug-resistant cells.
\end{abstract}

Keywords: multidrug resistance, paclitaxel, nanoparticles, micelles, nanospheres, P-glycoprotein

\section{Introduction}

There has been a great deal of interest in the development of amphiphilic block copolymer micelles for the delivery of the hydrophobic anticancer agent paclitaxel (PTX). ${ }^{1-3}$ Due to their amphiphilic nature, diblock copolymers are capable of self-assembling at the critical micelle concentration to form micelles characterized by a hydrophobic core surrounded by a highly water-bound corona. The core is usually composed of biocompatible, biodegradable polyesters such as poly(lactic acid) or poly(caprolactone) that solubilize PTX, and the hydrophilic polymer is typically methoxy poly(ethylene glycol) (MePEG). ${ }^{4}$ The micellar structure is considered dynamic, as there is equilibrium between unimers in solution and those participating in the nanoparticle structure, resulting in a "fluidlike" core. These systems offer several formulation advantages for the delivery of PTX. By eliminating the use of the solubilizing agent Cremophor-EL, currently used in the commercial formulation Taxol, any toxicity associated with the use
Correspondence: Helen M Burt Faculty of Pharmaceutical Sciences, University of British Columbia, 2I 46 East Mall, Vancouver, BC V6T IZ3, Canada

Tel +l 6048222440

Fax +l 6048223034

Email helen.burt@ubc.ca 
of this agent is prevented. Furthermore, copolymer micelles are capable of enhancing PTX solubility from $1 \mu \mathrm{g} / \mathrm{mL}$ in water to over $5 \mathrm{mg} / \mathrm{mL}$ in a micellar formulation. ${ }^{2}$ Although these nanosized structures might offer the potential for prolonged circulation and passive targeting of the drug, ${ }^{5}$ dynamic micelles are usually disrupted in the presence of biological milieu, resulting in the rapid release and elimination of their hydrophobic drug payload. ${ }^{6-9}$

Our group has investigated the use of the nanoparticles formed from MePEG-block-poly (caprolactone) (MePEG-bPCL) for the delivery of PTX. We have demonstrated that there is a shift in the physicochemical properties, and hence the performance of these nanoparticles as drug-delivery systems, as the molecular weight of the hydrophobic block increases. ${ }^{3}$ Two types of nanoparticles were fabricated using the same MePEG block length of 114 ethylene glycol repeat units, with either a short PCL block length of 19 caprolactone repeat units $\left(\mathrm{MePEG}_{114}-\mathrm{b}-\mathrm{PCL}_{19}\right.$ or PCL19) to form micelles, or a longer PCL block length of 104 repeat units (MePEG ${ }_{114}$-b-PCL ${ }_{104}$ or PCL104) to form kinetically "frozen core" structures termed nanospheres. We have shown that PCL104 nanospheres solubilize more PTX, release the drug at a more sustained rate and are more stable in the presence of human plasma as compared to their micelle counterparts, likely due to the "solid-like" core of these nanoparticles. ${ }^{3}$ However, whether the differences in the physicochemical properties and the stability of these nanoparticles affect the cellular uptake of loaded PTX or the copolymer themselves is not known.

Aside from the poor aqueous solubility, another significant barrier in the treatment of cancer with PTX is its efflux by P-glycoprotein (P-gp). P-gp is a transmembrane drug efflux protein and a member of the adenosine triphosphate (ATP)-binding cassette superfamily. P-gp is responsible for cellular multidrug resistance (MDR) to a wide variety of anticancer drugs, including PTX. ${ }^{10}$ Numerous strategies have been investigated to overcome the efflux of P-gp substrates, including the encapsulation of these drugs in nanoparticles to enable entry into cells by endocytosis and therefore bypassing Pgp. ${ }^{11,12}$ Additionally, the extensive work by Kabanov and co-workers has demonstrated that certain commercially available Pluronic amphiphilic agents are capable of inhibiting P-gp. ${ }^{13}$ This led to several reports evaluating multicomponent or mixed polymeric nanoparticles incorporating one or more Pluronics for both solubilizing taxanes and inhibiting P-gp function. ${ }^{14-17}$ However, the potential drawback of using Pluronics is the nondegradability and lack of renal excretion for high-molecular-weight members of this copolymer class. ${ }^{18,19}$ Previous work by our group has demonstrated that a very low-molecular-weight MePEG-bPCL copolymer (MePEG ${ }_{17}-\mathrm{b}-\mathrm{PCL}_{5}$ [PCL5]) is an effective modulator of P-gp. We reported on the ability of PCL5 used at concentrations above and below the critical micelle concentration $(0.03 \%)$ to enhance the accumulation of Pgp substrates, including PTX, in P-gp-overexpressing cell. ${ }^{20,21}$

Given the dual functionality of MePEG-b-PCL as micellar or nanosphere PTX carrier and P-gp modulator, depending only on block lengths, we postulated that the uptake and cytotoxicity of PTX-loaded MePEG-b-PCL nanoparticles in drug-sensitive or MDR cell lines would be dependent on the composition of the diblock copolymer carrier and coadministration of PCL5.

The objectives of this work were to evaluate the cellular uptake and cytotoxicity of PTX formulated in micelles (PCL19) or nanospheres (PCL104) and administered to drugsensitive (Madin-Darby Canine Kidney [MDCK]II) and drug-resistant (MDCKII-MDR1) cell lines, with or without exposure to the P-gp inhibitor PCL5. Our results show that PTX-loaded micelles are more effective than nanospheres in inhibiting proliferation in MDCKII-MDR1 cells, but are not different in MDCKII cells, and that there are dramatic effects on reversing chemoresistance in MDCKII-MDR1 cells in the presence of PCL5.

\section{Materials and methods Materials}

Paclitaxel (PolymedT, Houston, TX, USA), radioactive paclitaxel (Moravek Radiochemicals, Brea, CA, USA), tetramethylrhodamine-5-carbonyl azide, 4',6-diamino-2phenylindole dihydrochloride (DAPI) (Life Technologies, Carlsbad, CA, USA), Dulbecco's modified Eagle's medium supplemented with $5 \%$ fetal bovine serum and $1 \%$ penicillin/streptomycin, Hank's buffered salt solution (HBSS) (Life Technologies), MTS (3-[4,5-dimethylthiazol-2-yl]-5-[3carboxymethoxyphenyl]-2-[4-sulfophenyl]-2H-tetrazolium) cell-proliferation assay kit (Promega, Madison, WI, USA), cytotox 96 nonradioactive cytotoxicity assay (Promega), MePEG (Sigma-Aldrich, St Louis, MO, USA), bicinchoninic acid (BCA) protein assay kit (Thermo Fisher Scientific, Rockford, IL, USA), $\varepsilon$-caprolactone (Sigma-Aldrich), stannous octoate (Sigma-Aldrich), and $N, N$-dimethylformamide (DMF) (Thermo Fisher Scientific) were used as supplied without further purification. MDCKII and MDCKIIMDR1 cells were kind gifts from Dr Piet Borst (National Cancer Institute, Netherlands). Amphiphilic diblock copolymers composed of MePEG and poly(caprolactone) were 
synthesized and characterized as previously described., ${ }^{9,23}$ These copolymers are abbreviated $\mathrm{MePEG}_{\mathrm{m}}-\mathrm{b}-\mathrm{PCL}_{\mathrm{n}}$, where $m$ and $n$ are the number of repeat units of ethylene glycol and caprolactone, respectively. In these studies, three copolymers were investigated: $\mathrm{MePEG}_{114}$-b-PCL ${ }_{104}, \mathrm{MePEG}_{114}$-b-PCL 19 , and $\mathrm{MePEG}_{17}$-b-PCL ${ }_{5}$.

\section{Methods}

\section{Synthesis and characterization of MePEG-b-PCL} diblock copolymers

PCL5, PCL19, and PCL104 were synthesized and characterized as previously described and reported elsewhere. ${ }^{3}$ Briefly, MePEG with a molecular weight of either $750 \mathrm{~g} / \mathrm{mol}$ (PCL5) or $5000 \mathrm{~g} / \mathrm{mol}$ (PCL19 and PCL104) was combined with $\varepsilon$-caprolactone in weight ratios of either 60:40 (PCL5), 30:70 (PCL19), or 70:30 (PCL104) with a total mass of $50 \mathrm{~g}$. The reactants were reacted at $140^{\circ} \mathrm{C}$ for 4 hours (PCL5) or 24 hours (PCL19 and PCL104) in a sealed round-bottomed flask containing $35 \mathrm{~mL}$ of anhydrous toluene (Sigma-Aldrich) using $0.15 \mathrm{~mL}$ of stannous octoate as a catalyst. The products were purified by dissolving the copolymers in chloroform followed by precipitation with a 70/30 mix of hexane and diethyl ether. The molecular weight of the diblock copolymers was determined by gel permeation chromatography using poly(ethylene glycol) (Polymer Laboratories) as the standards in the range of $670-22,800 \mathrm{~g} / \mathrm{mol}$ using chloroform as a mobile phase with a flow rate of $1 \mathrm{~mL} /$ minute. Waters (Milford, MA, USA) Styragel columns (HR3 and HR1) connected in series were used, and the detection was through a Waters model 2410 refractive index detector. The compositions of the copolymers were determined by proton nuclear magnetic resonance spectra of $10 \% \mathrm{w} / \mathrm{v}$ solutions of the copolymers in deuterated chloroform, obtained from a $400 \mathrm{MHz}$ Advance II+ spectrometer (Bruker, Milton, ON). The spectra were analyzed using MestRe-C 2.3a software (freeware). The degree of polymerization of copolymers were calculated using peaks situated around 1.3 and $1.55 \mathrm{ppm}$ from the caprolactone methylene protons and the peaks at $3.55 \mathrm{ppm}$ from the MePEG methylene protons.

\section{Fluorescent labeling of MePEG-b-PCL copolymers}

The copolymers PCL19 and PCL104 were fluorescently labeled with tetramethylrhodamine-5-carbonyl azide (TMRCA), as described previously. ${ }^{24}$ Briefly, $20 \mathrm{mg}$ of PCL19 or PCL104 were reacted with $6 \mathrm{mg}$ of TMRCA in $20 \mathrm{~mL}$ of anhydrous toluene under a nitrogen atmosphere for 24 hours at $80^{\circ} \mathrm{C}$ in a sealed round-bottom flask. After termination of the reaction, the reaction mixture was placed in
3500 molecular weight cutoff (MWCO) SnakeSkin dialysis membranes (Thermo Fisher Scientific) and dialyzed against DMF for 1 week, with frequent exchanges of fresh DMF, to remove unreacted TMRCA. The dialysis tubing is made of high-performance regenerated cellulose, which has fair resistance to DMF. The dialysis tubing was changed several times to avoid the leakage of polymers. The mixture was then dialyzed against distilled water for 3 days to remove any organic solvent. The dialysis tube and distilled water were changed frequently, and the dialysis was terminated when no trace of rhodamine in the external solvent was detected. The aqueous mixture was then lyophilized. A small amount of the labeled copolymers was dissolved in DMF, and the TMRCA labeling efficiency of the diblock copolymers was determined by spectrofluorometry against a calibration curve of free TMRCA in DMF using a Synergy MX (Biotek, Winooski, VT, USA) fluorescence plate reader and a Nunc 96-well plate (Thermo Fisher Scientific) using an excitation wavelength of $548 \mathrm{~nm}$ and an emission wavelength of $572 \mathrm{~nm}$. The fluorescent labeling efficiency for PCL19 and PCL104 was approximately $50.3 \%$ and $63.3 \%$, respectively.

\section{Preparation of MePEG-b-PCL nanoparticles}

As previously described, a nanoprecipitation technique was used to prepare nanoparticles. ${ }^{3,9}$ Briefly, $30 \mathrm{mg}$ of either PCL104 or PCL19 was dissolved in $0.5 \mathrm{~mL}$ of DMF. In formulations in which PTX was to be included, $0.5 \mathrm{mg}$ of PTX was also added to the DMF solution. This solution was added drop-wise to $2 \mathrm{~mL}$ of rapidly stirring phosphate-buffered saline (PBS) (0.01 M, pH 7.4). The DMF was removed from the nanoparticle dispersion by dialysis overnight against $4 \mathrm{~L}$ of PBS using 3500 MWCO Spectra/Por dialysis membranes (Spectrum Labs, Rancho Dominguez, CA, USA). Following dialysis, the nanoparticle dispersions were made up to $3 \mathrm{~mL}$ with PBS. The drug loading was determined using a previously described high-performance liquid chromatography assay. ${ }^{25}$ As discussed in our previous publications, nanoparticles formed from PCL19 are referred to as micelles, whereas those formed from PCL104 are referred to as nanospheres.

\section{Cytotoxicity of MePEG-b-PCL block copolymers} MDCKII and MDCKII-MDR1 cells were seeded at 1500 cells/well in 96-well plates and allowed to grow overnight $\left(5 \% \mathrm{CO}_{2} / 95 \%\right.$ humidity at $\left.37^{\circ} \mathrm{C}\right)$ in modified Eagle's medium. To investigate the long-term cytotoxicity of the PCL19 or PCL104 nanoparticles or PCL5 with no drug present, the cells were incubated for 3 days in the presence of $200 \mu \mathrm{L}$ of PCL19 or PCL104, ranging in concentration from $0 \%$ to $0.4 \% \mathrm{w} / \mathrm{v}$ 
(0-4 mg/mL) or PCL5 from $0 \%$ to $5 \% \mathrm{w} / \mathrm{v}(0-50 \mathrm{mg} / \mathrm{mL})$, prepared in culture medium. As a control, cells were grown in culture medium in the absence of copolymer. Cell proliferation was measured using the MTS cell-proliferation assay kit according to the manufacturer's instructions. Cell viability was expressed as a percentage of the ratio of absorbance after treatment compared to the absorbance of control (no treatment). To assess any immediate cytotoxicity of PCL19, PCL104, or PCL5 diblock copolymers due to cell lysis, cells were incubated for 90 minutes with copolymers ranging in concentration from $0 \%$ to $5 \% \mathrm{w} / \mathrm{v}$. Cytotoxicity was measured using the lactate dehydrogenase (LDH)-release assay kit and $2 \%$ Triton X-100 was used as the positive control.

\section{Cytotoxicity of PTX-loaded MePEG-b-PCL nanoparticles}

Nanoprecipitation was used to prepare PCL19 micelles and PCL104 nanospheres, at a copolymer concentration of $1 \% \mathrm{w} / \mathrm{v}$ with a drug loading of $166 \mu \mathrm{g} / \mathrm{mL}$ PTX in PBS. These nanoparticles were subsequently diluted in culture media to prepare nanoparticle dispersions with PTX concentrations ranging from 2 to $32 \mu \mathrm{g} / \mathrm{mL}$ with a maximum copolymer concentration of $0.2 \% \mathrm{w} / \mathrm{v}$. MDCKII and MDCKII-MDR 1 cells were incubated in the presence of the PTX-loaded nanoparticles with these varying PTX loadings in culture media for 90 minutes or 3 days. Nanoparticles without drug were used as the control. To investigate whether coadministration of PTX-loaded micelles or nanospheres with PCL5 inhibits the proliferation of MDCKII and MDCKII-MDR1 cells, these cell lines were incubated with micelles or nanospheres with a PTX loading of $16 \mu \mathrm{g} / \mathrm{mL}$ and PCL5 at a concentration of $0.05 \% \mathrm{w} / \mathrm{v}$ in culture media for 3 days, followed by determination of cell viability by MTS assay. The effect of a sustained 3-day incubation of PCL5 at varying concentration after an initial 90-minute incubation with drug-loaded PCL19 micelles and PCL104 nanospheres was also investigated. Micelles and nanospheres prepared with a copolymer concentration of $0.2 \% \mathrm{w} / \mathrm{v}$ and a PTX loading of $32 \mu \mathrm{g} / \mathrm{mL}$ were first incubated with MDCKII and MDCKII-MDR 1 cells for 90 minutes and then removed, and the cells were washed with warm HBSS. Subsequently, the cells were incubated with PCL5 at concentrations between $0 \%$ and $0.25 \% \mathrm{w} / \mathrm{v}$ in culture media for 3 days to determine the concentration of PCL5 that was most effective at inhibiting cell proliferation after this short exposure to PTX-loaded nanoparticles. Cell viability was determined using the MTS cell-proliferation assay kit, as described above. The $\mathrm{IC}_{50}$ of PTX-loaded nanoparticles was then determined in the presence of PCL5 at this concentration. In order to do so, cells were first incubated for 90 minutes in the presence of nanoparticles loaded with PTX ranging in concentration from 0 to $60 \mu \mathrm{g} / \mathrm{mL}$. The drug-loaded formulations were then removed and the cells washed with $\mathrm{HBSS}$ at $37^{\circ} \mathrm{C}$, followed by incubation with $0.05 \% \mathrm{w} / \mathrm{v}$ PCL5 in culture media for 3 days. Cell viability was determined by MTS assay.

\section{Drug accumulation}

Micelles and nanospheres at a copolymer concentration of $0.2 \% \mathrm{w} / \mathrm{v}$ and a PTX concentration of $32 \mu \mathrm{g} / \mathrm{mL}$, along with a trace amount of ${ }^{3} \mathrm{H}-\mathrm{PTX}$, were prepared using the methods described above. MDCKII and MDCKII-MDR1 cells were plated in 48-well plates at a density of approximately 10,000 cells/well and grown for 2 days. Drug-loaded micelle and nanosphere dispersions were equilibrated for 30 minutes in a $37^{\circ} \mathrm{C}$ water bath, followed by addition to the cells and a 90-minute incubation. Following the incubation period, the supernatant was removed and the cells washed with ice-cold PBS to remove extracellular PTX. The cells were lysed with PBS containing $1.33 \%$ Triton X-100 and 33\% dimethyl sulfoxide, and the cell lysate was analyzed by $\beta$-scintillation counting using an LS6000TA scintillation counter (Beckman Instruments, Fullerton, CA, USA). A set of three wells per experimental plate was collected individually for total protein content as determined by BCA assay. The intracellular accumulation of PTX was quantified using calibration curves prepared from known concentrations of ${ }^{3} \mathrm{H}-\mathrm{PTX}$, and the concentration of PTX was normalized to total protein content.

\section{Polymer uptake and fluorescence confocal microscopy} Drug-loaded nanoparticles composed of TMRCA-labeled and -unlabeled PCL19 and PCL104 diblock copolymers with the same concentrations of TMRCA $(20 \mu \mathrm{M})$ were prepared using a nanoprecipitation method, as described above. MDCKII and MDCKII-MDR1 cells were seeded on poly-L-lysine-coated coverslips in 12-well plates at approximately 5000 cells/well and incubated overnight. TMRCA-labeled nanoparticle dispersions $(300 \mu \mathrm{L}$ of a $1 \mathrm{mg} / \mathrm{mL}$ dispersion) were incubated with cells for 90 minutes and washed once with an acidified wash $\left(0.5 \mathrm{M} \mathrm{NaCl}, 0.2 \mathrm{M} \mathrm{CH}_{3} \mathrm{COOH}, \mathrm{pH} 2.5\right)$ and once with HBSS (pH 7.4) to remove any surface associated copolymer. The coverslips with the adhered cells were removed from the plates, the cells were fixed with paraformaldehyde $(4 \%)$ on ice for 20 minutes, and the nuclei were stained with DAPI according to the manufacturer's instructions. The coverslips were then mounted cell-side-down on glass slides and microscopy studies were performed on a Fluoview FV-1000 (Olympus, 
Tokyo, Japan) inverted confocal microscope. The laser wavelengths used were 568 and $405 \mathrm{~nm}$ for imaging of TMRCA and DAPI, respectively. Direct contrast was also performed to visualize cell membranes and was activated with the $405 \mathrm{~nm}$ laser. All images were generated under the same microscope settings to allow for consistent comparison. The figures were created using FV10-ASW 3.0 software (Olympus). Approximately 50 confocal sections from the basal to the apical cell side were captured for Z-stacking analysis. To quantitate the amount of polymer taken up by cells, cells were seeded in 12-well culture plates, as described above, but without coverslips. After incubation with TMRCA-labeled nanoparticles, the cells were lysed with $1 \%$ Triton X-100 in HBSS. TMRCA copolymer was quantified by analyzing the cell lysate in a Synergy MX fluorescence plate reader (Biotek) with excitation at $548 \mathrm{~nm}$ and emission at $572 \mathrm{~nm}$, using a calibration curve of TMRCAlabeled copolymer in cell lysate solution over a concentration range of 25 to $150 \mu \mathrm{g} / \mathrm{mL}$. The intracellular content of the fluorescent-labeled polymer was expressed as the amount of polymer (mg) over the cellular protein content (mg) determined by BCA assay, as described above.

\section{Statistical analysis}

The experiments were performed in three individual experiments. The data are presented as mean \pm standard error of the mean. The data were analyzed by Student's $t$-test using Prism 5.0 software (GraphPad Software, La Jolla, CA, USA), with $P<0.05$ considered to be statistically significant.

\section{Results}

\section{Cytotoxicity of diblock copolymers}

The cytotoxicity of PCL19 micelles and PCL104 nanospheres over the concentration range of $0 \%-0.4 \%(\mathrm{w} / \mathrm{v})$ in the absence of drug was investigated for MDCKII and MDCKII-MDR1 cells. As shown in Figure 1, the cell viability of MDCKII and MDCKII-MDR1 cells after 3 days' incubation with the nanoparticulate formulations decreased slightly, to approximately $90 \%$ cell viability, with an increase in copolymer concentration above $0.1 \% \mathrm{w} / \mathrm{v}$. However, this decrease in cell viability was not statistically different to the cell-viability values determined at concentrations below $0.1 \% \mathrm{w} / \mathrm{v}$ copolymer. The short-term cytotoxicity of both PCL19 micelles and PCL104 nanospheres on MDCKII and MDCKII-MDR1 cell lines was determined using an LDHrelease assay, which indicates the amount of cell lysis over 90 minutes. As shown in Figure 2B, less than 3\% cell lysis was measured for all polymers and cell types up to a copolymer concentration of $1 \% \mathrm{w} / \mathrm{v}$. Residual DMF in the formulations
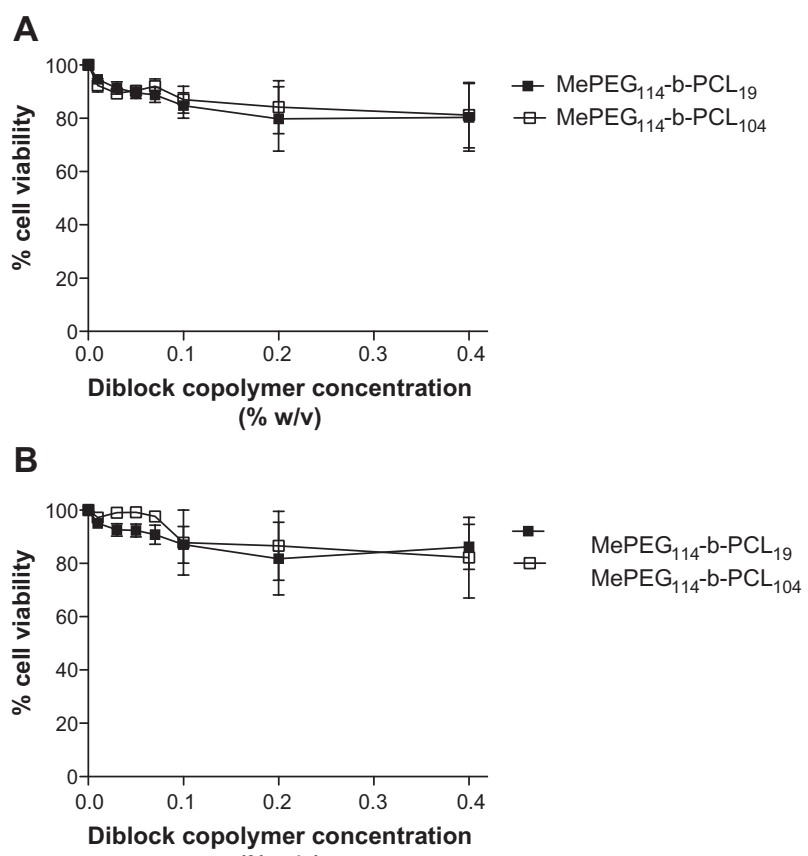

(\% w/v)

Figure I Cell viability of (A) MDCKII and (B) MDCKII-MDRI cells in the presence of various concentrations of $(\square) M_{\text {ePEG }}-{ }_{14}^{-b}-\mathrm{PCL}_{19}$ or $(\square) \mathrm{MePEG}_{114}-\mathrm{b}-\mathrm{PCL}_{104}$ diblock copolymer nanoparticles.

Notes: Cells were seeded in 96-well plates and treated with various concentrations of the nanoparticles for 3 days at $37^{\circ} \mathrm{C}$. Cell viability was determined using an MTS assay. Indicated values are mean ( \pm standard error of mean) of five independent experiments $(\mathrm{n}=5)$.

Abbreviations: MePEG-b-PCL, methoxy poly(ethylene glycol)-block-poly (caprolactone); MDCK, Madin-Darby Canine Kidney; MDR, multidrug-resistant; MTS, 3-(4,5-dimethylthiazol-2-yl)-5-(3-carboxymethoxyphenyl)-2-(4-sulfophenyl)-2$\mathrm{H}$-tetrazolium.

may be of concern when formulating nanoparticles by the nanoprecipitation and dialysis method, which may impact cell viability. In our formulations, the final concentration of DMF would be very low (calculated to be less than $0.005 \%$ ) due to rapid exchange of DMF with buffer, since the volume of buffer used was very large and the high MWCO of the dialysis membrane relative to the molecular weight of DMF. This small residual amount of DMF in the formulations did not appear to have a negative effect on the cells, as cell viability remained high across all concentrations tested (Figure 1).

\section{Influence of PCL5 on cell viability}

The influence of PCL5 on MDCKII and MDCKII-MDR1 cell viability was investigated by incubating the diblock copolymer at various concentrations with cells in the presence of culture medium for 3 days. The cell viability was measured using an MTS assay. As shown in Figure 3A, the viability of cells was unaffected by incubation with PCL5 at concentrations up to $1 \%(\mathrm{w} / \mathrm{v})$, beyond which cell viability rapidly declined. The immediate cytotoxicity of PCL5 on MDCKII and MDCKII-MDR1 cells was measured using the 

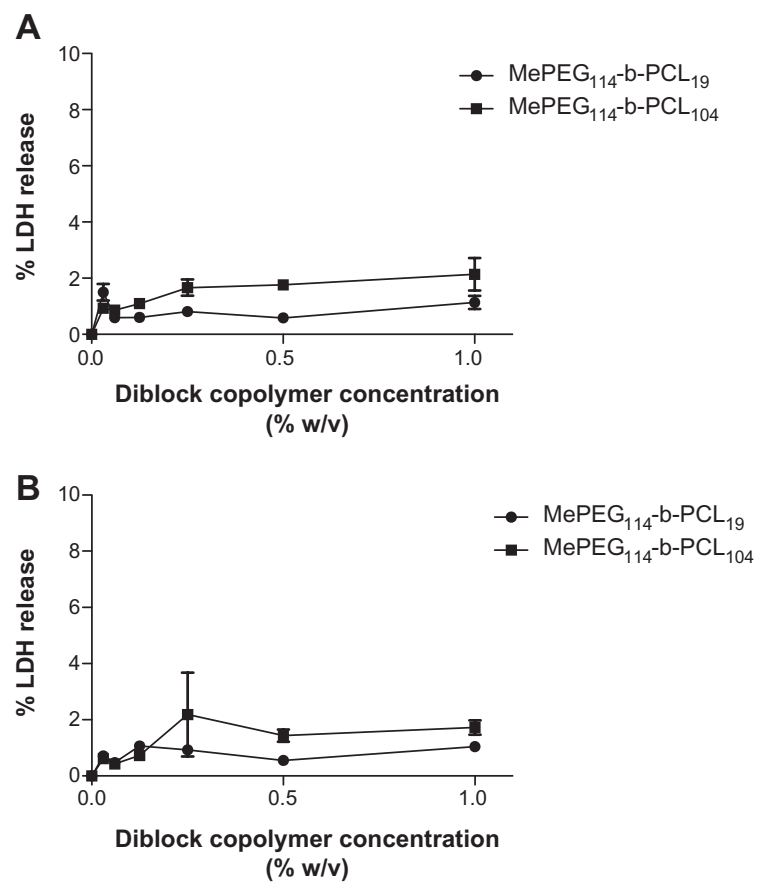

Figure 2 Cell lysis of (A) MDCKII and (B) MDCKII-MDRI cells treated with $(\bullet)$

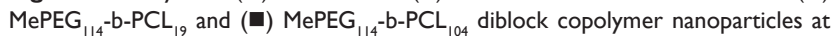
varying concentrations for 90 minutes.

Notes: Cell lysis was measured by LDH-release assay. The indicated values are the mean of three independent experiments ( \pm standard error of mean).

Abbreviations: MePEG-b-PCL, methoxy poly(ethylene glycol)-blockpoly(caprolactone); MDCK, Madin-Darby Canine Kidney; MDR, multidrug-resistant; MTS, 3-(4,5-dimethylthiazol-2-yl)-5-(3-carboxymethoxyphenyl)-2-(4-sulfophenyl)$2 \mathrm{H}$-tetrazolium; $\mathrm{LDH}$, lactate dehydrogenase.

LDH-release assay. As shown in Figure 3B, for both cell lines the amount of cell lysis was below $5 \%$ at diblock copolymer concentrations at or below $1 \% \mathrm{w} / \mathrm{v}$, beyond which the cell lysis gradually increased. No difference in cytotoxicity of PCL5 diblock copolymer between MDCKII and MDCKIIMDR1 cell lines was observed at concentrations up to $1 \%$. However, it appeared that the MDCKII-MDR1 cell line was more resistant to PCL5 at higher concentrations when compared to the MDCKII cell line.

\section{Cytotoxicity of PTX-loaded micelles and nanoparticles}

PTX was loaded into PCL19 micelles and PCL104 nanospheres using a previously reported nanoprecipitation method. ${ }^{3}$ It was previously determined that the maximum solubilization of PTX by PCL19 micelles was $1.7 \%$ $(\mathrm{w} / \mathrm{w})$ at an approximate $84 \%$ loading efficiency, whereas PCL104 nanospheres solubilized PTX at $2.5 \%(\mathrm{w} / \mathrm{w})$ with an approximate $85 \%$ loading efficiency. ${ }^{9}$ The cytotoxicity of PTX-loaded nanoparticles was investigated over a PTX concentration range from $2 \mu \mathrm{g} / \mathrm{mL}$ to $32 \mu \mathrm{g} / \mathrm{mL}$, with a maximum copolymer concentration of $0.2 \mathrm{w} / \mathrm{v}$ over a 3 -day
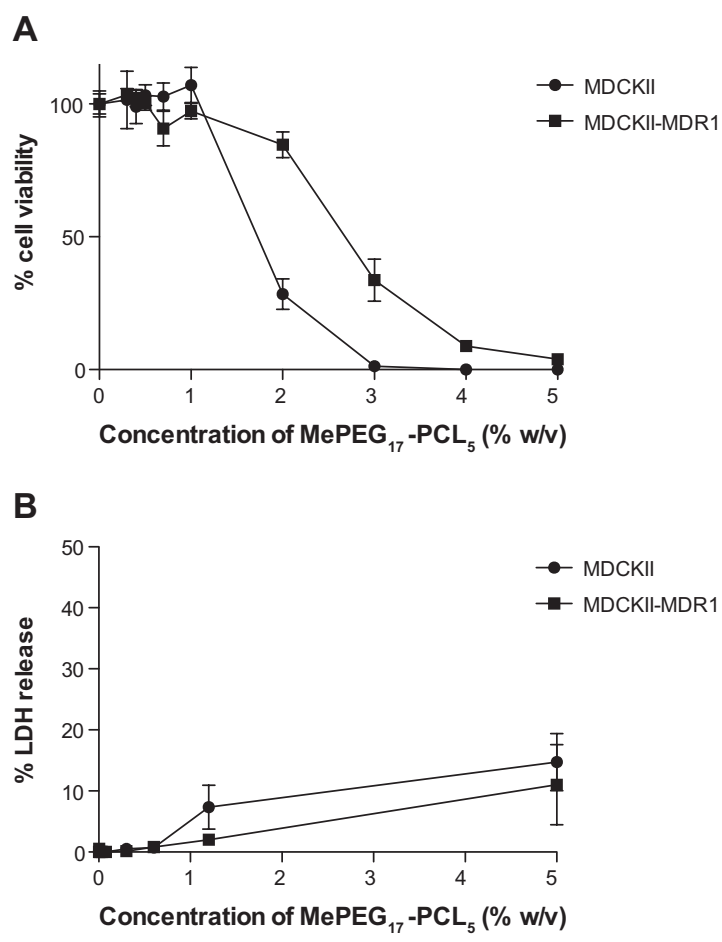

Figure 3 (A) Cell viability of $(\bullet)$ MDCKII and (घ) MDCKII-MDRI in the presence of $\mathrm{MePEG}_{17}-\mathrm{b}-\mathrm{PCL}_{5}$. The cells were incubated with various concentrations of $\mathrm{MePEG}_{17}-\mathrm{b}_{\mathrm{PCL}}$ for 3 days in culture medium, followed by determination of cell viability by MTS assay. (B) LDH release of $(\bullet)$ MDCKII and (ם) MDCKII-MDRI in the presence of $\mathrm{MePEG}_{17}-\mathrm{b}-\mathrm{PCL}_{5}$.

Notes: The cells were incubated with various concentrations of $\mathrm{MePEG}_{17}-\mathrm{b}-\mathrm{PCL}_{5}$ for 90 minutes in HBSS, followed by the LDH-release assay. The indicated values are the means of three independent experiments ( \pm standard error of mean).

Abbreviations: HBSS, Hank's buffered salt solution; MePEG-b-PCL, methoxy poly(ethylene glycol)-block-poly(caprolactone); MDCK, Madin-Darby Canine Kidney; MDR, multidrug-resistant; MTS, 3-(4,5-dimethylthiazol-2-yl)-5-(3-carboxymethoxyphenyl)-2-(4-sulfophenyl)-2H-tetrazolium; LDH, lactate dehydrogenase.

incubation period. The $\mathrm{IC}_{50}$ values of PTX-loaded micelles and nanospheres for MDCKII cells were found to be 1.4 and $1.9 \mu \mathrm{g} / \mathrm{mL}$, respectively (Figure 4A). The PCL19 PTXloaded micelles showed greater inhibition of proliferation of MDCKII-MDR1 compared to PCL104 PTX-loaded nanospheres (approximately $60 \%$ and $90 \%$ cell viability, respectively, at $32 \mu \mathrm{g} / \mathrm{mL}$ PTX loading) (Figure 4B). Due to the inability of these formulations to effectively inhibit the proliferation of MDCKII-MDR1 over the PTX concentration range tested, the $\mathrm{IC}_{50}$ for both nanoparticulate formulations could not be determined. The presence of the P-gp inhibitor cyclosporin A (CsA) resulted in greater than $90 \%$ inhibition of proliferation of MDCKII-MDR1 cell lines.

\section{Drug-accumulation studies}

The intracellular PTX accumulation in both MDCKII and MDCKII-MDR1 were investigated for incubations with both micellar and nanosphere PTX (Figure 5). Although it appeared that cells treated with PTX-loaded nanospheres 
A

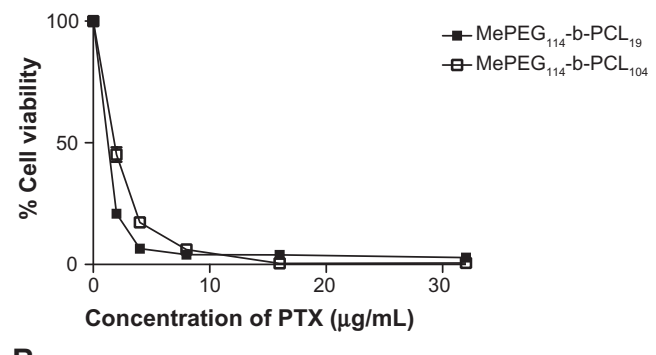

B

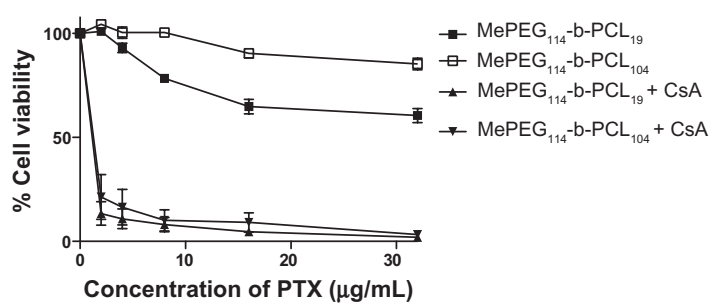

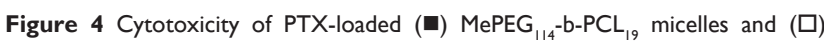
MePEG $_{114}-$ b-PCL $_{104}$ nanospheres in (A) MDCKII and (B) MDCKII-MDRI cell lines after 3 days' incubation.

Notes: The cell viability was determined by an MTS assay. The indicated values are the means of three independent experiments ( \pm standard error of mean).

Abbreviations: MePEG-b-PCL, methoxy poly(ethylene glycol)-blockpoly(caprolactone); CsA, cyclosporin A; MTS, 3-(4,5-dimethylthiazol-2-yl)-5-(3carboxymethoxyphenyl)-2-(4-sulfophenyl)-2H-tetrazolium; PTX, paclitaxel.

showed slightly higher PTX accumulation when compared to micelles, there was no statistical difference between micelles and nanospheres in both MDCKII and MDCKII-MDR1 cell lines $(P$-values $=0.34$ and 0.20 , respectively $)$.

\section{Polymer uptake and fluorescence confocal microscopy}

To quantify the amount of binding and/or cellular uptake of the two different copolymers, TMRCA-labeled copolymers

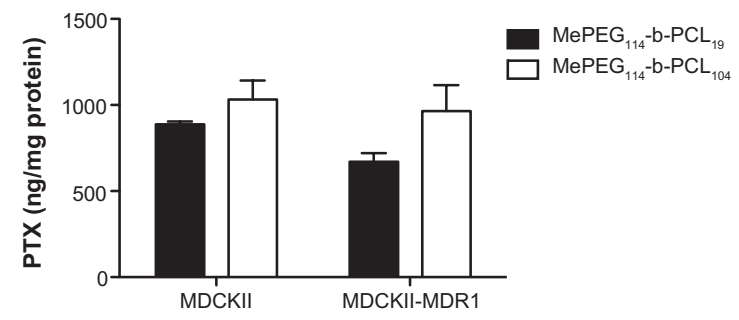

Figure 5 The intracellular accumulation of PTX delivered by MePEG $_{114}$-b-PCL micelles (black) and MePEG 114 -b-PCL ${ }_{104}$ nanospheres (white) in MDCKII and MDCKIIMDRI cells.

Notes: Cells were incubated with nanoparticulate PTX $(32 \mu \mathrm{g} / \mathrm{mL})$ for 90 minutes at $37^{\circ} \mathrm{C}$, followed by washing and lysis using $2 \%$ Triton X-100 in Hank's buffered salt solution. Intracellular PTX levels were measured using liquid scintillation counting of cell lysates. The intracellular PTX content was normalized to the total protein content, as determined by BCS assay. The indicated values are the means of three independent experiments ( \pm standard error of mean).

Abbreviations: MePEG-b-PCL, methoxy poly(ethylene glycol)-blockpoly(caprolactone); MDCK, Madin-Darby Canine Kidney; MDR, multidrug-resistant; PTX, paclitaxel. were incubated with the two cell lines, followed by quantification of the fluorescence using fluorescence spectroscopy. The association of PCL19 with MDCKII and MDCKIIMDR 1 cells ( 0.13 and $0.24 \mathrm{mg}$ polymer/mg protein, respectively) appeared to be higher than values for PCL104 (0.07 and $0.18 \mathrm{mg}$ polymer/mg protein, respectively), but there was no statistical significant difference $(P$-values $=0.10$ and 0.49 , respectively) (Figure 6). To evaluate whether the nanoparticles were internalized by cells or simply bound to the cell membrane of MDCKII and MDCKII-MDR1, confocal fluorescent microscopy was used. The presence of TMRCA-labeled PCL19 (Figure 7B and D) and PCL104 (Figure $7 \mathrm{~F}$ and $\mathrm{H}$ ) nanoparticles in the cytoplasm was shown by the red fluorescence of the polymer. The images in the left column of Figure 7 represented the cell contour using direct contrast. The internalization of nanoparticles was confirmed by the Z-stack analysis, demonstrating that the red fluorescent polymer is present throughout the cytoplasm rather than being only on the cell membrane. No autofluorescence of the cells was observed, and a negative control was performed in which the cells were treated with unlabeled nanoparticles, showing no red-fluorescence signal (data not shown).

\section{The effect of MePEG $_{19}-\mathrm{b}-\mathrm{PCL}_{5}$ on the cytotoxicity of PTX-loaded nanoparticles}

To investigate the ability of the P-gp modulator PCL5 to enhance the cytotoxicity of PTX-loaded nanoparticles in MDCKII cell lines, cells were treated with PTX-loaded micelles or nanospheres concurrently with PCL5 at a concentration of $0.05 \% \mathrm{w} / \mathrm{v}$ (Figure 8). As a positive control, PCL5 was substituted with $5 \mu \mathrm{M} \mathrm{CsA}$. Regardless of the treatment, the proliferation of MDCKII cells was effectively inhibited by PTX-loaded nanoparticles, with cell-viability values in

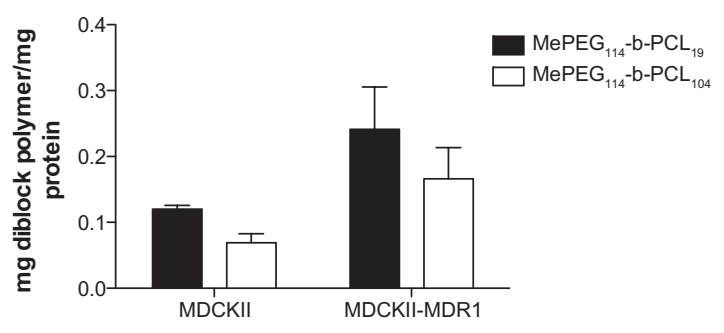

Figure 6 Intracellular concentration of TMRCA-labeled copolymers.

Notes: Cells were exposed to TMRCA-labeled micelles (black) or nanospheres (white) for 90 minutes at $37^{\circ} \mathrm{C}$. After the incubation period, cells were washed and lysed with $2 \%$ Triton X-100 in Hank's buffered salt solution. The amount of polymer bound or uptake into cells was determined by fluorescence spectroscopy. The indicated values are the means of three independent experiments ( \pm standard error of mean).

Abbreviations: MePEG-b-PCL, methoxy poly(ethylene glycol)-blockpoly(caprolactone); MDCK, Madin-Darby Canine Kidney; MDR, multidrug-resistant; TMRCA, tetramethylrhodamine-5-carbonyl azide. 

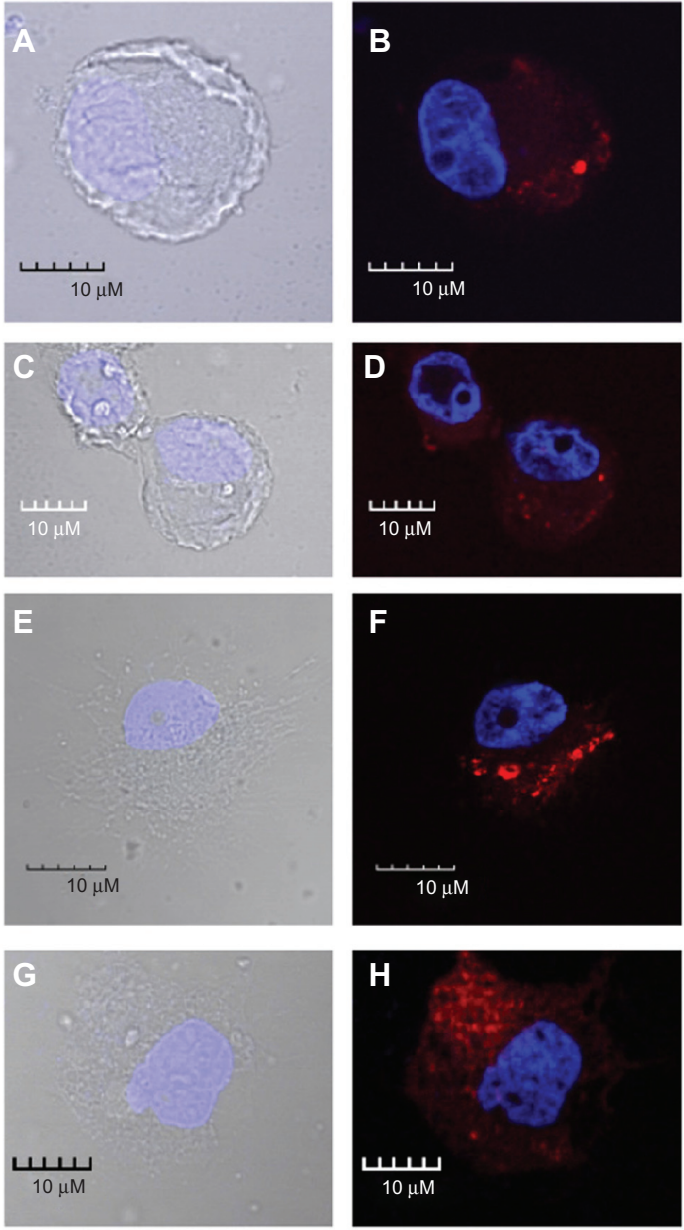

Figure 7 Confocal fluorescence imaging of $\operatorname{MDCKII}(\mathbf{A}, \mathbf{B}, \mathbf{E}$ and $\mathbf{F})$ and MDCKIIMDRI (C, D, G and $\mathbf{H}$ ) cells illustrating uptake of TMRCA-labeled MePEG $114^{\text {-b- }}$ $\mathrm{PCL}_{19}(\mathbf{A}-\mathbf{D})$ and $\mathrm{MePEG}_{114}$-b-PCL $\mathrm{PC}_{104}(\mathbf{E}-\mathrm{H})$ diblock copolymers after 90 minutes' incubation.

Notes: The images in the left column are an overlay of a direct contrast signal (which shows the contour of the cells) and the fluorescence of the nucleus (blue). The images in the right column demonstrate the overlay of fluorescence signal of the nucleus and the TMRCA-labeled diblock copolymers (red).

Abbreviations: MePEG-b-PCL, methoxy poly(ethylene glycol)-blockpoly(caprolactone); MDCK, Madin-Darby Canine Kidney; MDR, multidrug-resistant; TMRCA, tetramethylrhodamine-5-carbonyl azide.

the range of $10 \%-30 \%$. In the absence of PCL5 or CsA, MDCKII-MDR1 cell viability was found to be approximately $80 \%$ and $60 \%$ for treatment with PTX-loaded nanospheres and micelles, respectively. As a positive control, MDCKIIMDR1 cells were treated with PTX-loaded nanospheres or micelles with $5 \mu \mathrm{M}$ CsA, resulting in cell-viability values of approximately $50 \%$ and $25 \%$, respectively. Concurrent treatment with PTX-loaded micelles or nanospheres with $0.05 \% \mathrm{w} / \mathrm{v}$ PCL5 resulted in MDCKII-MDR1 viability of approximately $40 \%$.

Cells were then incubated with PTX $(32 \mu \mathrm{g} / \mathrm{mL})$-loaded PCL19 micelles or PCL104 nanospheres at a copolymer

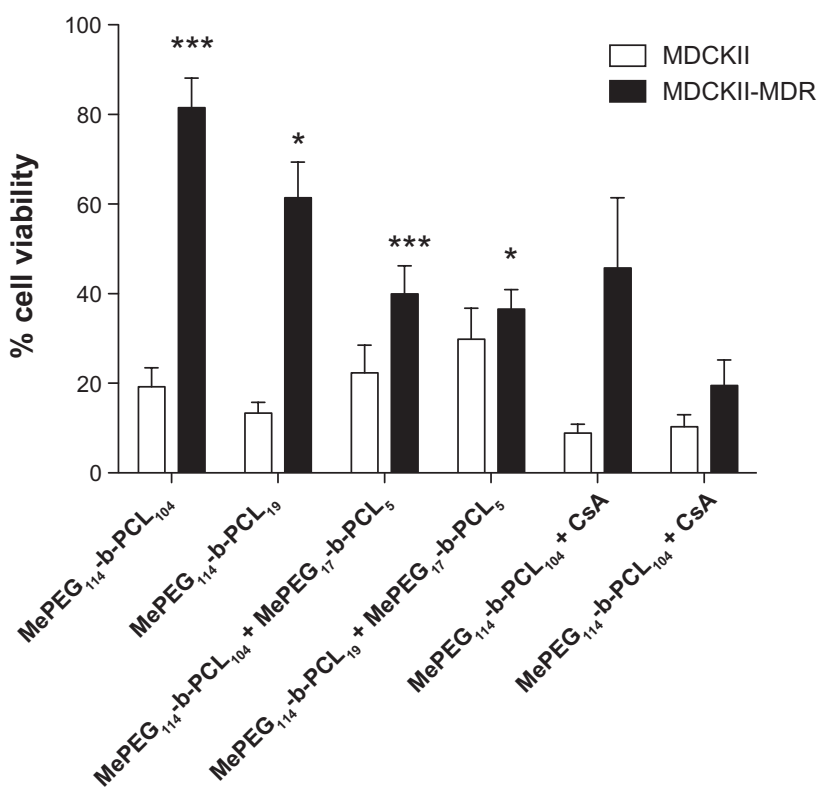

Figure 8 Cell viability of MDCKII (white) or MDCKII-MDRI (black) cells treated for 3 days with $\mathrm{MePEG}_{114}$-b-PCL ${ }_{19}$ micelles or $\mathrm{MePEG}_{114}-\mathrm{b}-\mathrm{PCL}_{104}$ nanospheres loaded with $16 \mu \mathrm{g} / \mathrm{mL}$ PTX with or without concurrent treatment with $(0.05 \% \mathrm{w} / \mathrm{v})$ $\mathrm{MePEG}_{17}-\mathrm{b}-\mathrm{PCL}_{5}$ or $(5 \mu \mathrm{M}) \mathrm{CsA}$.

Notes: The cell viability was determined by an MTS assay. The indicated values are the means of three independent experiments ( \pm standard error of mean). ***** $<0.05$.

Abbreviations: MePEG-b-PCL, methoxy poly(ethylene glycol)-blockpoly(caprolactone); MDCK, Madin-Darby Canine Kidney; MDR, multidrug-resistant; MTS, 3-(4,5-dimethylthiazol-2-yl)-5-(3-carboxymethoxyphenyl)-2-(4-sulfophenyl)$2 \mathrm{H}$-tetrazolium.

concentration of $0.2 \% \mathrm{w} / \mathrm{v}$ for 90 minutes, followed by extracellular washing/removal of the nanoparticulate dispersions and subsequent incubation with PCL5 diblock copolymer at concentrations up to $0.25 \% \mathrm{w} / \mathrm{v}$ in culture medium for 3 days. At this high concentration of PTX, both micellar and nanosphere formulations strongly inhibited MDCKII cell proliferation in the absence of PCL5, with a slight increase in cell viability as the PCL5 concentration increased (Figure 9A and B). The drug-resistant MDCKII-MDR1 cells displayed a higher degree of cell viability in the absence of PCL5 compared to MDCKII. However, with an increase in PCL5 concentration, there was a significant decrease in the viability of these cells (Figure 9), with minimum cell viability occurring at PCL5 diblock copolymer concentrations above $0.05 \% \mathrm{w} / \mathrm{v}$ for both the micelles and nanospheres. This low cell viability of MDCKII-MDR1 cells was similar to that of MDCKII at the same PCL5 concentration. Low concentrations of PCL5 resulted in a higher degree of cell viability for PCL104 nanospheres compared to cells incubated in the presence PCL19 micelles until PCL5 concentrations above $0.05 \%$ were reached, at which point cell viability remained at approximately $20 \%$.

To determine the $\mathrm{IC}_{50}$ of PTX-loaded nanoparticles in the presence of PCL5 at the concentration of maximal 
A
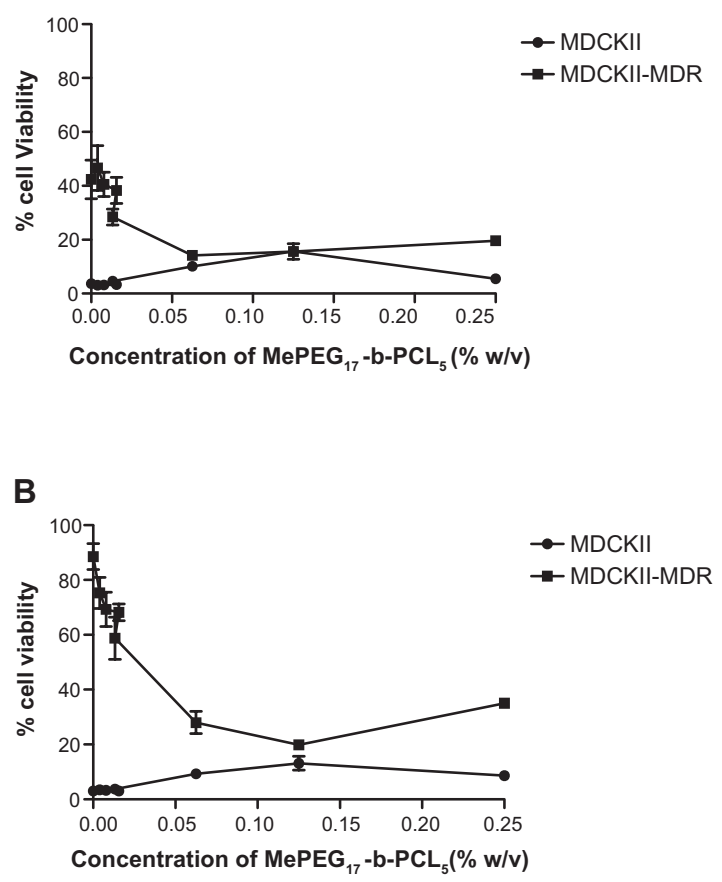

Figure 9 The effect of $\mathrm{MePEG}_{17}$-b-PCL $\mathrm{PL}_{5}$ diblock copolymer on the cytotoxicity of PTX-loaded (A) MePEG $114-\mathrm{b}-\mathrm{PCL}_{19}$ micelles and (B) MePEG 114 -b-PCL ${ }_{104}$ nanospheres. $(\bullet)$ MDCKII and (ロ) MDCKII-MDRI were incubated with PTX-loaded nanoparticles at a drug concentration of $32 \mu \mathrm{g} / \mathrm{mL}$ and copolymer concentration of $0.2 \% \mathrm{w} / \mathrm{v}$ for 90 minutes, followed by removal of the drug-loaded nanoparticle and a subsequent 3-day incubation in various concentrations of $\mathrm{MePEG}_{17}-\mathrm{b}-\mathrm{PCL}_{5}$.

Notes: The cell viability was determined by an MTS assay. The indicated values are the means of three independent experiments ( \pm standard error of mean).

Abbreviations: MePEG-b-PCL, methoxy poly(ethylene glycol)-blockpoly(caprolactone); MDCK, Madin-Darby Canine Kidney; MDR, multidrug-resistant MTS, 3-(4,5-dimethylthiazol-2-yl)-5-(3-carboxymethoxyphenyl)-2-(4-sulfophenyl)$2 \mathrm{H}$-tetrazolium; PTX, paclitaxel.

inhibition of cell proliferation found in the previous experiment $(0.05 \% \mathrm{w} / \mathrm{v})$, both MDCKII and MDCKII-MDR1 were pretreated with PTX-loaded micelles or nanospheres at various drug concentrations for 90 minutes, followed by removal of the drug-loaded formulations and subsequent incubation with PCL5 at $0.05 \% \mathrm{w} / \mathrm{v}$ in the presence of culture medium for 3 days. The presence or absence of PCL5 did not significantly affect the $\mathrm{IC}_{50}$ for MDCKII treated with PTX-loaded PCL19 micelles (Figure 10A). Interestingly, incubation of MDCKII-MDR1 cells with PTX-loaded PCL19 micelles followed by subsequent incubation with PCL5 resulted in the significant decrease in $\mathrm{IC}_{50}$ of this formulation to a level that was comparable to that obtained with treatment of MDCKII with the same formulation (Figure 10A). Treatment of MDCKII with PTX-loaded PCL104 nanospheres with subsequent incubation with PCL5 resulted in a slightly higher $\mathrm{IC}_{50}$ than treatment without PCL5 (Figure 10B). Incubation of MDCKII-MDR1 cells with PTX-loaded PCL104 nanospheres did not result in any decrease in cell viability; however,
A

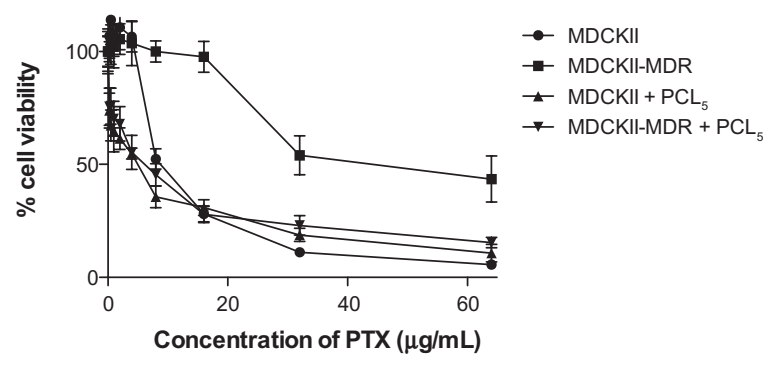

B

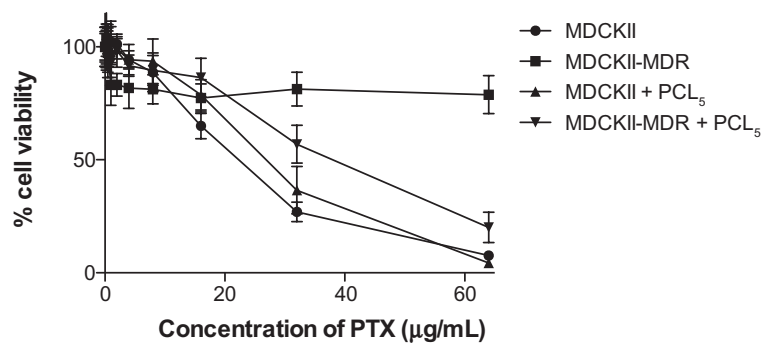

Figure 10 The cytotoxicity of PTX-loaded (A) MePEG $114-\mathrm{b}-\mathrm{PCL}_{19}$ micelles and (b) MePEG $_{114}-\mathrm{b}-\mathrm{PCL}_{104}$ nanospheres in MDCKII and MDCKII-MDRI cells with and without subsequent incubation with $\mathrm{MePEG}_{17}-\mathrm{b}-\mathrm{PCL}_{5}$.

Notes: Cells were treated with PTX-loaded micelles and nanospheres with varying concentrations of PTX for 90 minutes, followed by removal of the drug-loaded nanoparticles and a subsequent 3-day incubation with media with or without $0.05 \%$ $w / v M^{2} E_{17}-b-P C L_{5}$. Cell viability was determined by an MTS assay. The indicated values are the means of three independent experiments ( \pm standard error of mean). Abbreviations: MePEG-b-PCL, methoxy poly(ethylene glycol)-blockpoly(caprolactone); MDCK, Madin-Darby Canine Kidney; MDR, multidrug-resistant; MTS, 3-(4,5-dimethylthiazol-2-yl)-5-(3-carboxymethoxyphenyl)-2-(4-sulfophenyl)2H-tetrazolium; PTX, paclitaxel.

subsequent incubation with PCL5 resulted in significant inhibition of cell proliferation (Figure 10B). The $\mathrm{IC}_{50}$ of this group was not as low as the $\mathrm{IC}_{50}$ for the group first incubated with PCL19 followed by incubation with PCL5.

\section{Discussion}

Our previous reports have focused on the physicochemical characterization of PCL19 and PCL104, and their performance as drug-delivery vehicles for PTX. ${ }^{3,9}$ We demonstrated that PCL104 nanospheres solubilized a greater amount of PTX, released the drug at a slower rate, and exhibited enhanced stability and retention of PTX in human plasma. ${ }^{3}$ The current work expands upon the previous reports and investigates the differences in these PTX-loaded nanoparticulate carriers with respect to their ability to inhibit cell proliferation of drug-sensitive and -resistant P-gp-overexpressing cell lines MDCKII and MDCKII-MDR1, respectively. Additionally, we investigated whether concurrent and subsequent administration of PCL5 with these drug-loaded nanoparticles resulted in enhanced inhibition of cellular proliferation. For these studies, we evaluated our formulations using the MDCKII 
and MDCKII-MDR1 cell lines, as this pair is a good model for the study of P-gp substrates/inhibitors. ${ }^{26,27}$

\section{Cellular biocompatibility of MePEG-b-PCL}

The determination of the biocompatibility of the three MePEG-b-PCL diblock copolymers (PCL104, PCL19, and PCL5) in MDCKII and MDCKII-MDR1 cells was required to define the concentration of polymer tolerated by the cells in order to evaluate the cytotoxicity of drug-loaded formulations in subsequent experiments. Our results demonstrated that MePEG-b-PCL diblock copolymers are well tolerated by the MDCKII and MDCKII-MDR1 cell lines, with little or no cytotoxicity of either cell line for concentrations of PCL104 or PCL19 up to $0.4 \% \mathrm{w} / \mathrm{v}$ (Figure 1). This high degree of biocompatibility of MePEG-b-PCL diblock copolymers was also reported by other groups in several different cell lines, including erythrocyte, breast cancer, pheochromocytoma, and cervical cancer cells. ${ }^{3,28,29}$ The short-term-cytotoxicity study also suggested that the PCL19 and PCL104 copolymers did not cause a high degree of cell lysis, as indicated by low LDH release (Figure 2). Similar to PCL19 and PCL104 copolymers, both short- and long-term cell-viability assays demonstrated that the PCL5 copolymer did not cause cell death at concentrations up to $1 \%(\mathrm{w} / \mathrm{v})$, suggesting that this copolymer is also highly biocompatible with MDCKII and MDCKII-MDR1 cell lines (Figure 3A and B). In previous studies using NCI/ADR-RES cells, we demonstrated that cell death occurred beyond a PCL5 concentration of $0.1 \% \mathrm{w} / \mathrm{v},{ }^{20}$ whereas in Caco-2 cells, lysis was not observed until concentrations exceeded $0.5 \%{ }^{30}$ These previous results, in combination with our current results, indicate that the cellular biocompatibility of these copolymers may vary dependent on the particular cell line used.

\section{Cytotoxicity of PTX-loaded nanoparticles}

PTX-loaded nanoparticles effectively inhibited the proliferation of MDCKII cells (Figure 4A), but MDCKII-MDR1 cells demonstrated significant resistance to the drug, as exhibited by the high degree of cell viability, regardless of the concentration of PTX used (Figure 4B). However, treatment of MDCKII-MDR1 cells with PTX-loaded nanoparticles in the presence of the recognized P-gp inhibitor $\mathrm{CsA}^{10}$ resulted in a rapid decline in cell viability with increased PTX loadings, establishing that the high degree of resistance to PTX treatment was due to the upregulation of P-gp in this cell line. Figure 4B shows that PTX loaded micelles (PCL19) were more effective than nanosphere (PCL104)-encapsulated PTX at inhibiting the proliferation of MDCKII-MDR1 cells.
This was unlikely due to any differences in the total amount of PTX delivered to the cells, as there was no statistical difference between drug-accumulation levels in cells incubated with either nanosphere or micelle formulations (Figure 5).

In the present study, the fact that the nanospheres were shown to have a higher $\mathrm{IC}_{50}$ yet delivered approximately the same amount of total drug as the micelles leads us to speculate that a fraction of the drug is still associated with intracellular PCL104 and therefore not available to bind to $\beta$-tubulin, the intracellular target of PTX. In order for this concept to be feasible, cellular uptake of the copolymer is a prerequisite. Cellular uptake of the copolymers was quantified using a spectrofluorometric assay (Figure 6) and observed visually by confocal microscopy (Figure 7). Both PCL19 and PCL104 copolymers were associated with both MDCKII and MDCKII-MDR1 cells (Figures 6 and 7) providing some evidence for intact nanoparticulate uptake. It is not known why the MDR cells took up more copolymer than the MDCKII cells. However, whilst MDCKII and MDCKII-MDR1 are very similar in nature, there are likely large differences in protein content between the cells, and the copolymer uptake in Figure 6 is expressed as a function of protein content. For both the nanospheres and micelles, MDCKII and MDCKII-MDR1 cells clearly displayed red cytoplasmic staining due to the TMRCA-labeled copolymer, indicating association of the copolymers with the cells (Figure 7). Z-stacking verified that that this staining was located in the cytosol and not located in the plasma membrane or in the nuclear compartment of the cells.

Consistent with our findings, Savic et al also demonstrated that poly(ethylene oxide) ( $\mathrm{PEO})_{45}-\mathrm{b}_{-}-\mathrm{PCL}_{23}$ labeled with TMRCA was localized in the cytoplasm. ${ }^{31}$ Additional studies using a fluorogenic dye conjugated to $\mathrm{PEO}_{45}-\mathrm{b}-\mathrm{PCL}_{21}$ demonstrated that micelles formed from these copolymers for the most part retained their integrity upon uptake by T24 bladder carcinoma cells. ${ }^{7}$ Several groups have also demonstrated that block copolymers are internalized by cells, primarily via endocytotic mechanisms. ${ }^{24,32}$ On the other hand, in a series of Förster resonance energy transfer (FRET) studies using KB cells and MePEG-b-PLA and MePEG-b-PCL micelles, Chen et al provided evidence that hydrophobic fluorescent probes solubilized in these micelles rapidly partitioned into the plasma membrane of KB cells, followed by uptake of FRET by endocytosis. ${ }^{6}$ Similar findings were reported for the mechanism of uptake of the hydrophobic dye Nile red by Xiao et al, but with some evidence of copolymer association with the membrane. ${ }^{33}$ It must be kept in mind that different polymers, cell lines, and surface charges of nanoparticles may result in varying degrees and mechanisms of uptake. ${ }^{34}$ 


\section{The effect of PCL5 on the cytotoxicity of PTX-loaded nanoparticles}

We investigated the ability of PTX-loaded PCL19 micelles or PCL104 nanospheres to inhibit cell proliferation of MDCKII cell lines when concurrently administered with the P-gp modulators PCL5 or CsA for 3 days (Figure 8). Treatment of MDCKII cells resulted in low cell viability regardless of the nanoparticulate carrier used or whether a P-gp modulator was present, as expected. MDCKII-MDR1 cells treated with either PTX-loaded micelles or nanospheres in the absence of PCL5 or CsA resulted in considerably higher cell-viability values compared to the MDCKII group. The presence of CsA or PCL5 decreased the cell viability of MDCKII-MDR1 to about the same extent, confirming the usefulness of PCL5 as a P-gp inhibitor when used in combination with micelles and nanospheres.

The short-term (90-minute) incubation of PTX-loaded micelles and nanospheres, with a $32 \mu \mathrm{g} / \mathrm{mL}$ drug loading, followed by washing, produced a rapid and high intracellular loading of PTX. Subsequent incubation in drug-free culture media for 3 days without PCL5 effectively inhibited the proliferation of MDCKII cells (Figure 9). The slight increase in the MDCKII cell viability when the copolymer concentration was above $0.05 \% \mathrm{w} / \mathrm{v}$ was not found to be significant, and the cytotoxicity of PTX was determined to be more than $80 \%$ over the full PCL5 concentration range. In the absence of PCL5, MDCKII-MDR1 cell viability remained relatively high, and treatment with micelles was slightly more effective at inhibiting cell proliferation than nanospheres (Figure 9). Subsequent incubation of MDCKII-MDR 1 cells with increasing concentrations of PCL5 resulted in a copolymer dosedependent decrease in cell viability, with the most effective PCL5 concentrations above $0.05 \% \mathrm{w} / \mathrm{v}$ (Figure 9). The key finding presented in the current study is that PTX-loaded MePEG-b-PCL nanoparticles are capable of delivering enough PTX during a short 90-minute incubation period to effectively inhibit cell proliferation of MDCKII-MDR1 cells, provided that PCL5 is present continuously throughout the subsequent 3-day incubation period at a concentration above $0.05 \% \mathrm{w} / \mathrm{v}$.

Although the mechanism by which PCL inhibits P-gp is not entirely clear, previous studies indicate that PCL5 can penetrate cell membranes and increase P-gp ATPase activity. ${ }^{35}$ It was speculated that the stimulation of the ATPase might reflect an ability of the copolymer to interact directly with P-gp, leading to inhibition. It has been proposed that nonionic surfactants inhibit/modulate P-gp by various mechanisms, including changing membrane fluidity, inhibiting P-gp
ATPase activity, and depleting ATP stores..$^{36-40}$ Interestingly, as we have previously demonstrated, if PCL5 is not maintained above an inhibitory concentration, PTX rapidly effluxes from the MDCKII-MDR1 cells, resulting in reduced inhibition of cell proliferation. ${ }^{20}$

An additional experiment was conducted to determine the $\mathrm{IC}_{50}$ of PTX-loaded nanospheres or micelles in the presence of PCL5 at its most effective concentration $(0.05 \%)$. The results from Figure 10 show that the subsequent incubation with PCL5 copolymer did not affect the $\mathrm{IC}_{50}$ in MDCKII cells treated with either PTX-loaded micelles or nanospheres. Treatment of MDCKII-MDR1 cells with PTX-loaded micelles or nanospheres along with subsequent incubation with $0.05 \%$ PCL5 resulted in a significant reduction in the cell viability of these cells. PTX-loaded micelles resulted in a lower $\mathrm{IC}_{50}$ than drug-loaded nanospheres, which we speculate is due to a higher fraction of PTX bound to an intracellular pool of PCL104 and less free intracellular PTX available to bind to $\beta$-tubulin in the nanosphere formulation.

The use of mixed nanoparticle systems that carry both a cytotoxic drug and a polymeric P-gp inhibitor to overcome MDR has been previously reported using a variety of Pluronic block copolymers. ${ }^{14-17}$ However, in recent studies by Zhang et al, ${ }^{16}$ blank Pluronic P123/F127 mixed polymeric micelles were demonstrated to be toxic at relatively low concentrations $(0.1 \% \mathrm{w} / \mathrm{v})$ compared to the copolymers investigated in this study, which do not induce cytotoxicity below $1 \% \mathrm{w} / \mathrm{v}$. We suggest that the greater cellular biocompatibility along with the biodegradability of MePEG-b-PCL may be a potential advantage, allowing for higher dosing of drug and copolymer.

\section{Conclusion}

In this study, we demonstrated that the cytotoxicity of PTXloaded MePEG-b-PCL nanoparticles is dependent on the hydrophobic block length of the carrier, with shorter hydrophobic block length copolymer (PCL19) micelles demonstrating greater cytotoxicity in MDR cells. Importantly, PCL5 coadministered with PTX-loaded nanoparticles dramatically enhanced the cytotoxicity of PTX in drug-resistant cells. Further studies are in progress to formulate mixed-molecular-weight copolymer nanoparticles, in which MePEG-b-PCL serves as the carrier and both PCL5 and PTX are coloaded in the nanoparticles to achieve intracellular sustained release of both components with the goal of overcoming drug resistance in cancer cells.

\section{Acknowledgments}

These studies were financially supported by an operating grant from the Canadian Institutes of Health Research (CIHR) 
awarded to Dr Helen Burt. The authors would like to thank Dr Padmesh Rajput, Lindsay Heller, and the Center for Drug Research and Development (CDRD) for the use of their laser confocal microscope. We would also like to thank Karanvir Sall, Nathan Wong, and Winnie Ye for their assistance in sample preparation.

\section{Disclosure}

The authors report no conflicts of interest in this work.

\section{References}

1. Sarisozen C, Vural I, Levchenko T, Hincal AA, Torchilin VP. PEGPE-based micelles co-loaded with paclitaxel and cyclosporine A or loaded with paclitaxel and targeted by anticancer antibody overcome drug resistance in cancer cells. Drug Deliv. 2012;19(4):169-176.

2. Zhang XC, Jackson JK, Burt HM. Development of amphiphilic diblock copolymers as micellar carriers of taxol. Int J Pharm. 1996;132(1-2):195-206.

3. Letchford $\mathrm{K}$, Liggins $\mathrm{R}$, Wasan KM, Burt $\mathrm{H}$. In vitro human plasma distribution of nanoparticulate paclitaxel is dependent on the physicochemical properties of poly(ethylene glycol)-blockpoly(caprolactone) nanoparticles. Eur J Pharm Biopharm. 2009; 71(2):196-206.

4. Gaucher G, Dufresne MH, Sant VP, Kang N, Maysinger D, Leroux JC. Block copolymer micelles: preparation, characterization and application in drug delivery. J Control Release. 2005;109(1-3):169-188.

5. Iyer AK, Khaled G, Fang J, Maeda H. Exploiting the enhanced permeability and retention effect for tumor targeting. Drug Discov Today. 2006;11(17-18):812-818.

6. Chen H, Kim S, He W, et al. Fast release of lipophilic agents from circulating PEG-PDLLA micelles revealed by in vivo forster resonance energy transfer imaging. Langmuir. 2008;24(10):5213-5217.

7. Savic R, Azzam T, Eisenberg A, Maysinger D. Assessment of the integrity of poly(caprolactone)-b-poly(ethylene oxide) micelles under biological conditions: a fluorogenic-based approach. Langmuir. 2006;22(8):3570-3578.

8. Chen H, Kim S, Li L, Wang S, Park K, Cheng JX. Release of hydrophobic molecules from polymer micelles into cell membranes revealed by Forster resonance energy transfer imaging. Proc Natl Acad Sci US A. 2008;105(18):6596-6601.

9. Letchford K, Burt HM. Copolymer micelles and nanospheres with different in vitro stability demonstrate similar paclitaxel pharmacokinetics. Mol Pharm. 2012;9(2):248-260.

10. Szakacs G, Paterson JK, Ludwig JA, Booth-Genthe C, Gottesman MM. Targeting multidrug resistance in cancer. Nat Rev Drug Discov. 2006; 5(3):219-234.

11. Yan Y, Ochs CJ, Such GK, Heath JK, Nice EC, Caruso F. Bypassing multidrug resistance in cancer cells with biodegradable polymer capsules. Adv Mater. 2010;22(47):5398-5403.

12. Lee Y, Graeser R, Kratz F, Geckeler KE. Paclitaxel-loaded polymer nanoparticles for the reversal of multidrug resistance in breast cancer cells. Adv Mater. 2011;21(22):4211-4218.

13. Kabanov AV, Batrakova EV, Alakhov VY. Pluronic block copolymers for overcoming drug resistance in cancer. Adv Drug Deliv Rev. 2002; 54(5):759-779.

14. Mei L, Zhang Y, Zheng Y, et al. A novel docetaxel-loaded poly (epsilon-caprolactone)/Pluronic F68 nanoparticle overcoming multidrug resistance for breast cancer treatment. Nanoscale Res Lett. 2009;4(12): $1530-1539$

15. Mu CF, Balakrishnan P, Cui FD, et al. The effects of mixed MPEG-PLA/Pluronic copolymer micelles on the bioavailability and multidrug resistance of docetaxel. Biomaterials. 2010;31(8): $2371-2379$
16. Zhang W, Shi Y, Chen Y, Ye J, Sha X, Fang X. Multifunctional Pluronic P123/F127 mixed polymeric micelles loaded with paclitaxel for the treatment of multidrug resistant tumors. Biomaterials. 2011;32(11): 2894-2906.

17. Zhang Y, Tang L, Sun L, et al. A novel paclitaxel-loaded poly(epsiloncaprolactone)/Poloxamer 188 blend nanoparticle overcoming multidrug resistance for cancer treatment. Acta Biomater. 2010;6(6): 2045-2052.

18. Besheer A, Vogel J, Glanz D, Kressler J, Groth T, Mader K. Characterization of PLGA nanospheres stabilized with amphiphilic polymers: hydrophobically modified hydroxyethyl starch vs pluronics. Mol Pharm. 2009;6(2):407-415.

19. Ruel-Gariepy E, Leroux JC. In situ-forming hydrogels - review of temperature-sensitive systems. Eur J Pharm Biopharm. 2004;58(2): 409-426.

20. Elamanchili P, McEachern C, Burt H. Reversal of multidrug resistance by methoxypolyethylene glycol-block-polycaprolactone diblock copolymers through the inhibition of P-glycoprotein function. J Pharm Sci. 2009;98(3):945-958.

21. Zastre JA, Jackson JK, Wong W, Burt HM. P-glycoprotein efflux inhibition by amphiphilic diblock copolymers: relationship between copolymer concentration and substrate hydrophobicity. Mol Pharm. 2008;5(4):643-653.

22. Letchford K, Liggins R, Burt H. Solubilization of hydrophobic drugs by methoxy poly(ethylene glycol)-block-polycaprolactone diblock copolymer micelles: theoretical and experimental data and correlations. J Pharm Sci. 2008;97(3):1179-1190.

23. Letchford K, Zastre J, Liggins R, Burt H. Synthesis and micellar characterization of short block length methoxy poly(ethylene glycol)-blockpoly(caprolactone) diblock copolymers. Colloids Surf B Biointerfaces. 2004;35(2):81-91.

24. Luo L, Tam J, Maysinger D, Eisenberg A. Cellular internalization of poly(ethylene oxide)-b-poly(epsilon-caprolactone) diblock copolymer micelles. Bioconjug Chem. 2002;13(6):1259-1265.

25. Liggins RT, D’Amours S, Demetrick JS, Machan LS, Burt HM. Paclitaxel loaded poly(L-lactic acid) microspheres for the prevention of intraperitoneal carcinomatosis after a surgical repair and tumor cell spill. Biomaterials. 2000;21(19):1959-1969.

26. Tang F, Horie K, Borchardt RT. Are MDCK cells transfected with the human MDR1 gene a good model of the human intestinal mucosa? Pharm Res. 2002;19(6):765-772.

27. Taub ME, Podila L, Ely D, Almeida I. Functional assessment of multiple P-glycoprotein (P-gp) probe substrates: influence of cell line and modulator concentration on P-gp activity. Drug Metab Dispos. 2005;33(11):1679-1687.

28. Allen C, Yu Y, Maysinger D, Eisenberg A. Polycaprolactone-bpoly(ethylene oxide) block copolymer micelles as a novel drug delivery vehicle for neurotrophic agents FK506 and L-685,818. Bioconjug Chem. 1998;9(5):564-572.

29. Zhang W, Li Y, Liu L, et al. Amphiphilic toothbrushlike copolymers based on poly(ethylene glycol) and poly(epsilon-caprolactone) as drug carriers with enhanced properties. Biomacromolecules. 2010;11(5): 1331-1338.

30. Zastre J, Jackson J, Bajwa M, Liggins R, Iqbal F, Burt H. Enhanced cellular accumulation of a P-glycoprotein substrate, rhodamine-123, by Caco-2 cells using low molecular weight methoxypolyethylene glycolblock-polycaprolactone diblock copolymers. Eur J Pharm Biopharm. 2002;54(3):299-309.

31. Savic R, Luo L, Eisenberg A, Maysinger D. Micellar nanocontainers distribute to defined cytoplasmic organelles. Science. 2003;300(5619): 615-618.

32. Sahay G, Batrakova EV, Kabanov AV. Different internalization pathways of polymeric micelles and unimers and their effects on vesicular transport. Bioconjug Chem. 2008;19(10):2023-2029.

33. Xiao L, Xiong X, Sun X, et al. Role of cellular uptake in the reversal of multidrug resistance by PEG-b-PLA polymeric micelles. Biomaterials. 2011;32(22):5148-5157. 
34. Sahay G, Alakhova DY, Kabanov AV. Endocytosis of nanomedicines. J Control Release. 2010;145(3):182-195.

35. Zastre J, Jackson JK, Wong W, Burt HM. Methoxypolyethylene glycolblock-polycaprolactone diblock copolymers reduce P-glycoprotein efflux in the absence of a membrane fluidization effect while stimulating P-glycoprotein ATPase activity. J Pharm Sci. 2007;96(4):864-875.

36. Dudeja PK, Anderson KM, Harris JS, Buckingham L, Coon JS. Reversal of multidrug resistance phenotype by surfactants: relationship to membrane lipid fluidity. Arch Biochem Biophys. 1995;319(1):309-315.

37. Regev R, AssarafYG, Eytan GD. Membrane fluidization by ether, other anesthetics, and certain agents abolishes P-glycoprotein ATPase activity and modulates efflux from multidrug-resistant cells. Eur J Biochem. 1999;259(1-2):18-24.
38. Kabanov AV, Batrakova EV, Alakhov VY. An essential relationship between ATP depletion and chemosensitizing activity of Pluronic block copolymers. J Control Release. 2003;91(1-2):75-83.

39. Collnot EM, Baldes C, Wempe MF, et al. Influence of vitamin E TPGS poly(ethylene glycol) chain length on apical efflux transporters in Caco-2 cell monolayers. J Control Release. 2006;111(1-2):35-40.

40. Collnot EM, Baldes C, Schaefer UF, Edgar KJ, Wempe MF, Lehr CM. Vitamin E TPGS P-glycoprotein inhibition mechanism: influence on conformational flexibility, intracellular ATP levels, and role of time and site of access. Mol Pharm. 2010;7(3):642-651.
International Journal of Nanomedicine

\section{Publish your work in this journal}

The International Journal of Nanomedicine is an international, peerreviewed journal focusing on the application of nanotechnology in diagnostics, therapeutics, and drug delivery systems throughout the biomedical field. This journal is indexed on PubMed Central, MedLine, CAS, SciSearch ${ }^{\circledR}$, Current Contents ${ }^{\circledR} /$ Clinical Medicine,

\section{Dovepress}

Journal Citation Reports/Science Edition, EMBase, Scopus and the Elsevier Bibliographic databases. The manuscript management system is completely online and includes a very quick and fair peer-review system, which is all easy to use. Visit http://www.dovepress.com/ testimonials.php to read real quotes from published authors.

Submit your manuscript here: http://www.dovepress.com/international-journal-of-nanomedicine-journal 